\title{
PROTOCOLO COVID-19 PARA HIGIENIZAÇÃO DE PROFISSIONAIS DE SAÚDE NO DOMICÍLIO
}

\author{
Vitor Gomes de Matos Gomes ${ }^{1}$ \\ Pâmela Costa Pinto dos Santos ${ }^{1}$ \\ https://orcid.org/0000-0001-5553-3005 \\ https://orcid.org/0000-0002-8361-1784
}

Objetivo: desenvolver um protocolo de higienização de profissional de saúde no domicílio, a fim de padronizar o processo e desenvolver uma lista de checagem (checklist) das etapas a serem realizadas pelo profissional de saúde para sua descontaminação baseada no protocolo desenvolvido. Método: Pesquisa de produção tecnológica, com enfoque em inovação. Utilizou-se da metodologia exploratória descritiva para realizar busca pelos temas Prevenção da COVID-19; Boas práticas de higienização; e Métodos de desinfecção, além das pesquisas sobre enfrentamento ao COVID-19. Essas produções foram analisadas e tornaram-se base teórica para desenvolvimento de um protocolo e checklist de higienização. Resultado: Obteve-se um protocolo sintetizado em um checklist de 19 passos capaz de reduzir a transmissão do vírus SARS-COV2 dos profissionais de saúde para os ambientes domiciliares e seus contactantes domésticos. Este protocolo se mostrou útil, não só a ser realizado pelos profissionais de saúde, como também aos profissionais expostos a COVID-19 em outros ambientes e até à população em geral. Conclusão: As etapas do protocolo e suas recomendações são simples de serem seguidas, assim como seus insumos são de fácil aquisição. Este protocolo se mostrou útil, não só a ser realizado pelos profissionais de saúde, como também aos profissionais expostos a COVID-19 em outros ambientes e até a população em geral.

Descritores: Infecções por coronavirus; Contenção de riscos biológicos; Prevenção de doenças; Pandemia; Saúde Pública.

\section{COVID-19 PROTOCOL FOR HYGIENIZING HEALTHCARE PROFESSIONALS AT HOME}

Objective: to develop a health professional hygiene protocol at home, in order to standardize the process and develop a checklist of the steps to be performed by the health professional for their decontamination based on the developed protocol. Method: Technological production research, focusing on innovation. The descriptive exploratory methodology was used to search for the COVID-19 Prevention themes; Good hygiene practices; and Disinfection methods, in addition to the research on coping with COVID-19. These productions were analyzed and became a theoretical basis for the development of a hygiene checklist and protocol. Result: A protocol synthesized in a 19-step checklist was obtained, capable of reducing the transmission of the SARS-COV2 virus from health professionals to the home environment and their domestic contacts. This protocol proved to be useful, not only to be performed by health professionals, but also to professionals exposed to COVID-19 in other environments and even to the population in general. Conclusion: The steps of the protocol and its recommendations are simple to follow, as well as its inputs are easy to acquire. This protocol proved to be useful, not only to be performed by health professionals, but also to professionals exposed to COVID-19 in other environments and even the population in general.

Descriptors: Coronavirus Infections; Containment of Biohazards; disease prevention; Pandemics; Public Health

\section{PROTOCOLO COVID-19 PARA HIGIENIZAR A LOS PROFESIONALES DE LA SALUD EN EL HOGAR}

Objetivo: desarrollar un protocolo de higiene de profesionales de la salud en el hogar, para estandarizar el proceso y desarrollar una lista de verificación de los pasos que debe realizar el profesional de la salud para su descontaminación con base en el protocolo desarrollado. Método: Investigación de producción tecnológica, centrada en la innovación. La metodología exploratoria descriptiva se utilizó para buscar los temas de Prevención de COVID-19; Buenas prácticas de higiene; y Métodos de desinfección, además de la investigación sobre cómo hacer frente a COVID-19. Estas producciones fueron analizadas y se convirtieron en una base teórica para el desarrollo de una lista de verificación y protocolo de higiene. Resultado: se obtuvo un protocolo sintetizado en una lista de verificación de 19 pasos, capaz de reducir la transmisión del virus SARS-COV2 de los profesionales de la salud al entorno doméstico y sus contactos domésticos. Este protocolo demostró ser útil, no solo para ser realizado por profesionales de la salud, sino también por profesionales expuestos a COVID-19 en otros entornos e incluso a la población en general. Conclusión: los pasos del protocolo y sus recomendaciones son fáciles de seguir, así como sus entradas son fáciles de adquirir. Este protocolo demostró ser útil, no solo para ser realizado por profesionales de la salud, sino también por profesionales expuestos a COVID-19 en otros entornos e incluso a la población en general.

Descriptores: Infecciones por Coronavirus; Contención de riesgos biológicos; Prevención de enfermedades; Pandemía; Salud Públic.

'Universidade do Estado do Rio de Janeiro, RJ.

Autor Correspondente: Vitor Gomes de Matos Gomes Email: vitor.gomes.matos@hotmail.com Recebido: 22/4/2020 Aceito: 28/5/2020 


\section{INTRODUÇÃO}

A transmissão da COVID-19 se iniciou em 2019 em Wuhan, na China, e já se tornou preocupante pela rápida propagação do vírus e pelo desconhecimento acerca de sua real proporção. Em março de 2020, a Organização Mundial da Saúde declarou como Pandemia a disseminação internacional COVID-19, que na época se tratava de 118.326 casos confirmados e 4.292 óbitos pelo vírus'. Atualmente, apenas 38 dias depois de decretado a pandemia, foram registrados 2.160.207 casos confirmados e 146.088 óbitos, demonstrando o grave descontrole sobre o panorama da saúde mundial. Este rápido crescimento requer medidas para reduzir a propagação do vírus SARS-COV-2, causador da doença conhecida como COVID-19, de forma eficiente.

As medidas de higiene básica são primordiais para o controle e redução da propagação e se mostram efetivas, não apenas da COVID-19, como também de diversos patógenos que hoje estão no meio comum da comunidade ${ }^{2}$. Medidas estas como higienização das mãos com água e sabão ou soluções antissépticas, higiene corporal e capilar, limpeza dos ambientes domésticos e das roupas reduzem consideravelmente as doenças e já é conhecida pela Enfermagem há séculos ${ }^{3}$

Em várias situações, os patógenos são transportados pelos profissionais de saúde do ambiente hospitalar para o comunitário e, principalmente o doméstico. Por tanto, exige-se redobrado esforço destes profissionais com o cuidado ao chegar a casa com o processo de descontaminação de roupas e acessórios e maior atenção ainda no período pandêmico da COVID-19.

Entretanto, em um levantamento de dados realizado pelos autores nos meses de abril e maio com a estratégia de busca (("COVID 19" or "coronavírus" or "infecções por coronavírus" or "sars-cov-2") and "prevenção\&controle" and "pessoal da saúde"), foi encontrado um total de 87 produções completas em português, inglês e espanhol. Porém nenhuma aborda um protocolo que os profissionais da saúde devam realizar para higienização em domicílio, o que justifica desenvolver um protocolo padronizado. Portanto, este estudo é relevante por ser inovador na temática, além de ser extremamente necessária na atual pandemia, ampliando as ações de controle da COVID-19 e favorecendo o desenvolvimento científico.

Para solucionar o problema da contaminação dos profissionais de saúde e seus familiares, este trabalho tem como objetivo desenvolver um protocolo de higienização no domicílio de profissional de saúde com fundamentação científica, a fim de padronizar o processo, facilitando a completa higienização e redução da propagação de patógenos. Também, desenvolver uma lista de checagem (checklist) das etapas a serem realizadas pelo profissional de saúde para sua descontaminação, por ordem de sequência, baseada no protocolo desenvolvido.

\section{METODOLOGIA}

Pesquisa de produção tecnológica, com enfoque em inovação. Utilizou-se da metodologia exploratória descritiva para realizar busca pela produção científica publicada por órgãos nacionais brasileiros e pela Organização Mundial da Saúde OMS, além das pesquisas sobre COVID-19 disponibilizadas na página oficial da OMS e através do metabuscador da Coordenadoria de Aperfeiçoamento de Pessoal do Ensino Superior - CAPES sobre os temas: Prevenção da COVID-19; Boas práticas de higienização; e Métodos de desinfecção. Essas produções foram analisadas para extrair a base teórica para desenvolvimento de um protocolo com etapas a serem seguidas com suas respectivas justificativas, assim como determinação dos materiais empregados e técnicas a serem realizadas. Posteriormente, as etapas foram organizadas em formato lista de checagem (checklist), permitindo a impressão desta e seu sequenciamento de etapas.

\section{O Protocolo de Higienização em Domicilio}

Neste trabalho, objetiva-se a higienização do profissional e dos eventuais fômites a nível residencial, para proteção do próprio profissional de saúde e de seus familiares. Entretanto, considera-se importante também a prevenção da contaminação na comunidade e em ambientes que possam recontaminar o profissional em outros momentos. Desta forma, foi necessário que este protocolo fosse dividido em dois períodos: o período pré-residencial e o período residencial.

O periodo pré-residencial é formado por etapas com a finalidade de reduzir a contaminação dos transportes públicos e particulares e dos ambientes comuns, assim como tornar o processo de descontaminação na residência mais efetivo. Como exemplo, estas primeiras medidas têm a capacidade de reduzir as chances de contaminação dos veículos particulares e através desta redução, torna-se mais difícil contaminar um familiar que utilize o mesmo veículo em outro momento. Entretanto estas etapas não são consideradas obrigatórias e sim recomendações, dado que o objetivo deste protocolo é reduzir o risco de contaminação da moradia do profissional e, consequentemente, seus familiares.

Inicia-se a fase pré-residencial com a retirada completa dos acessórios que podem ser considerados fômites que tenham sido utilizados durante o período de trabalho: estetoscópios, canetas, crachás de identificação, óculos de proteção individual, dentre outros. O mesmo deve ocorrer com roupas hospitalares (jalecos e pijamas) ainda no ambiente hospitalar. 
Recomenda-se que as roupas hospitalares sejam guardadas do avesso, pois a transmissão da COVID-19 ocorre principalmente por gotículas e aerossóis ${ }^{4}$ e, sendo estas partículas pequenas para atravessar a roupa hospitalar pela absorção do próprio tecido, a face da roupa exposta ao ambiente é considerada mais contaminada do que a face interna. As roupas hospitalares devem ser guardadas dentro de um saco plástico para evitar contato com outros itens na bolsa do profissional. Porta-jalecos pode ser utilizado, desde que possa e seja lavado após o uso. Ressalta-se que tanto estes sacos quantos os porta-jalecos não poderão ser reutilizados para acondicionamento de roupas limpas sem a devida higienização.

Nas unidades hospitalares que possuírem vestiários com chuveiros para uso dos profissionais, recomenda-se que o profissional realize uma higiene básica, um banho de aspersão simples, com o intuito de reduzir a taxa de patógenos no corpo ${ }^{5}$. Neste momento se deve focar principalmente na fricção com água e sabão nas áreas corporais descobertas pela roupa hospitalar: face e pescoço, membros superiores e tornozelos. No impeditivo do banho de aspersão, realizar a higienização facial que reduz parcialmente a contaminação pessoal. As roupas pessoais do profissional também devem ser trocadas por roupas limpas trazidas de casa, sendo que as roupas trocadas devem ser acondicionadas no mesmo saco que a roupa hospitalar. O indicado é utilizar as roupas disponibilizadas pelas unidades de internação, como exigido pela Norma Regulamentadora $32^{6}$, pois o hospital tem a capacidade de processar corretamente este tipo de material. Com estas medidas tomadas, reduz-se consideravelmente a transmissão do agente SARS COV-2 e outros nocivos à saúde, aumentando as chances de contenção da pandemia.

Atualmente, é recomendado o uso de máscaras, sejam descartáveis ou de fabricação caseira, para redução de propagação de gotículas ${ }^{7}$. Após a pré-descontaminação, o profissional deve utilizar um destes tipos de máscaras para se locomover nos ambientes públicos até sua residência.

O período residencial consiste em etapas subsequentes obrigatórias e que devem ser totalmente cumpridas antes de seguir para a próxima. Alguns preparativos prévios devem ser tomados. É necessário determinar um balde grande ou outro recipiente passivel de higienização e colocar um saco que cubra toda a área interna e que cubra a borda do balde até cerca de um quarto de sua altura (Figura 1). Dar preferência à saco transparente, mas outros também poderão ser utilizados. Este balde servirá para isolar a roupa contaminada a fim de evitar a exposição do ambiente limpo da casa. Também pode se colocar um recipiente plástico para depositar os acessórios possivelmente contaminados. O mais próximo da porta de entrada da residência, um rolo de papel toalha ou higiênico deve ser colocado para utilização exclusivamente de descontaminação neste protocolo.

A porta de entrada deve ser formada por um perímetro de segurança, de um metro de comprimento tanto para o ambiente externo quanto para o ambiente interno. Se necessário, este perímetro pode ser determinado com fita adesiva no chão ou traçado com uma linha imaginária.

O primeiro passo deste protocolo inicia-se antes da chegada ao domicílio. Quando o profissional estiver se aproximando de sua residência, aproximadamente 10 minutos antes, o mesmo deve comunicar a sua chegada aos residentes de sua própria casa. Este passo tem duas finalidades: A primeira é preparar o ambiente para a sua chegada, fazendo com que os moradores evitem manter-se no ambiente da sala e banheiro, a transitar por estes ambientes e conter crianças e animais que porventura venham a abraçar ou beijar e entrar em contato com o profissional antes da sua descontaminação ao final do protocolo. Segunda, para que um dos moradores possa auxiliar no processo, posicionando um ventilador contra a porta. Caso o profissional resida sozinho, esta etapa pode ser ignorada.

Ao chegar à residência, o profissional deve manter a chave pendurada na fechadura para futura higienização e a porta deve ser mantida completamente aberta. Ao ligar, o ventilador deve ser posicionado na altura dos ombros do profissional, a cerca de 2 metros de distância, com o fluxo de ar contra o profissional, principalmente após a remoção da máscara. Como a principal transmissão da COVID-19 ocorre principalmente por meio de gotículas e aerossóis ${ }^{5}$, o fluxo de ar direcionado do ventilador contra profissional é um recurso para que eventuais partículas liberadas sejam impelidas para um ambiente externo. $\bigcirc$ fluxo de ar direcionado para ambientes externos é uma recomendação para controle ambiental ${ }^{8}$ e o uso do ventilador é uma solução doméstica mais próxima ao objetivo preconizado e acessivel disponível. O profissional deve tomar outras medidas acessórias, como evitar ao máximo falar até o fim do protocolo para evitar a formação de gotículas.

A solução antisséptica recomendada neste protocolo deve ser álcool líquido a 70\%. Dentre vários antissépticos testados com eficácia na eliminação do vírus ${ }^{9,10}$, considera-se o álcool com concentração entre 60 e $80 \%$ para uso neste protocolo, já que esta solução não descolore nem causa manchas em roupas e superfícies, é eficiente em tecido, madeira, vidro entre outros materiais, tem ação rápida e por ser um produto barato e de fácil acesso. Também, o antisséptico deve ser líquido, pois o veículo gel do álcool antisséptico para as mãos podem formar uma película que favoreça o acúmulo de sujidades nas superfícies. 
No perímetro de segurança externo, o profissional deve retirar todos os fômites como chaves, carteira e celulares, incluindo os crachás de identificação. O álcool 70\% deve ser aplicado sobre a superfície destes acessórios com o uso de um borrifador e friccionando com o papel toalha que fora previamente separado. O borrifador permite que o spray de álcool preencha toda a superfície, principalmente aquelas com relevo irregular e reentrâncias como em fechos e zíperes. Só após a higienização de toda a superfície, os itens podem ser colocados no recipiente plástico para aguardar a completa secagem do álcool e o término da higienização. Todo material que adentrar na casa deve ter passado pelo processo de desinfecção e não poderá entrar em contato com o profissional até o término do protocolo.

Bolsas e mochilas devem ser desinfectadas borrifando álcool 70\% em toda a superfície. Estudos indicam que a ação exclusiva do álcool tem ação desinfetante, pelas interações das partes polares e apolares do etanol sobre a barreira fosfolipídica do patógeno propiciando a morte deste e a fricção alcoólica torna a desinfecção pelo álcool mais eficiente ${ }^{11}$. Entretanto nem todos os itens podem ser friccionados, como o caso de algumas bolsas. Neste caso, devem sofrer dupla desinfecção, borrifando o álcool uma segunda vez após a secagem. Entre a primeira e a segunda aplicação, as roupas hospitalares nela contidas devem ser colocadas no saco dentro do balde.

As roupas pessoais do profissional devem ser retiradas logo após a desinfecção dos acessórios e bolsas. Blusas e calças devem ser retiradas e colocadas juntamente com as demais dentro do balde, respeitando o perímetro de segurança determinado. O mesmo deve ocorrer com a máscara utilizada, para futura higienização. Quando toda a roupa que estiver contaminada for depositada no balde, o saco deve ser fechado utilizando as bordas externas que não entraram em contato com as roupas (Figura 1). Isto impede a contaminação acidental de outras pessoas que porventura manipulem o balde, permitindo transportá-lo com mais segurança. Quando o saco é fechado corretamente, podem-se estimar as regiões que estão provavelmente contaminadas. O saco no recipiente deve ser encaminhado para área de serviço, em local pouco movimentado. Caso as roupas não possam ser lavadas imediatamente, o saco deve ser mantido fechado e exposto ao sol. Não existem evidências quanto a COVID-19 à exposição do sol, entretanto alguns patógenos não sobrevivem quando expostos à radiação UV solar por determinado período, já comprovados a outras classes virais, o que pode ser aplicado ao vírus da COVID-19 em nível teórico ${ }^{12-14}$.É nesta situação em que o uso do saco transparente é recomendado, já que sacos coloridos podem filtrar a radiação solar parcial ou totalmente.

Figura 1 - Saco em recipiente para roupas, técnica de fechamento e regiões possivelmente contaminadas.
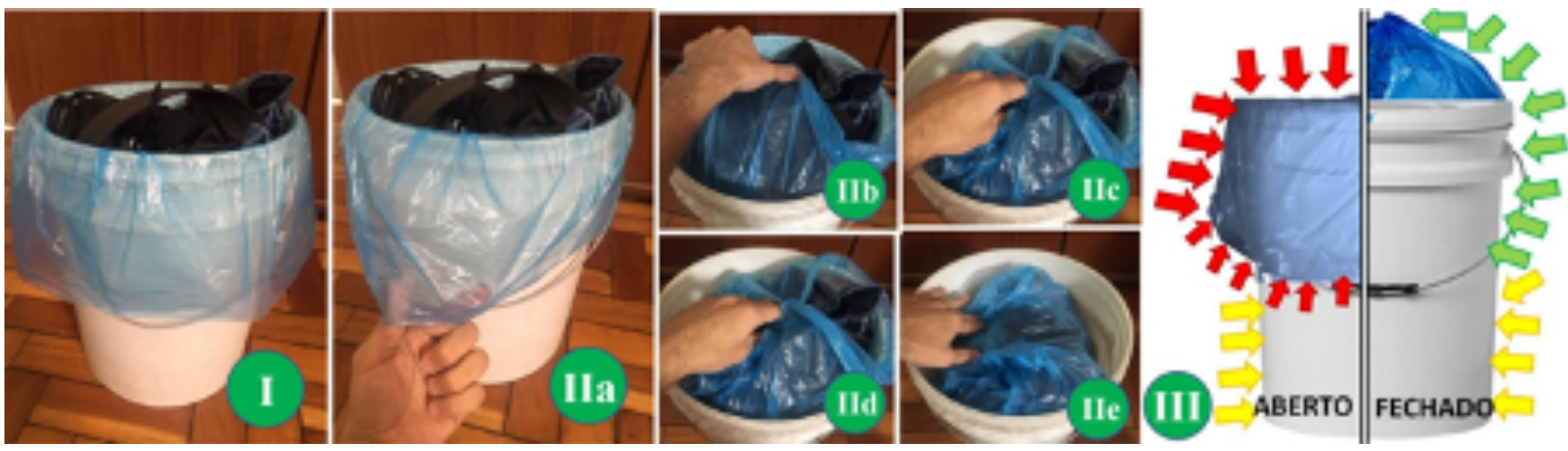

Fonte: Os autores, 2020

I: O saco é colocado cobrindo mais de $1 / 4$ do balde. IIa: Deve segurar o saco pela face externa, em contato com balde e sem contato com as roupas. As abas se sobrepõem como em IIb, c, d,e. III: As setas indicam as regiões contaminadas com o saco aberto e fechado na técnica: em verde, provavelmente não contaminado; em amarelo, possivelmente contaminado e; em vermelho, muito provavelmente contaminado.

Quando este passo estiver realizado, deve-se borrifar álcool $70 \%$ ou hipoclorito a $1 \%$ em todo o perímetro de segurança. O calçado utilizado deve sofrer a mesma desinfecção com o borrifador e, se possível, deve ser armazenado em ambiente externo. Para a desinfecção exclusivamente do perímetro de segurança e de sapatos emborrachados, poderá ser empregado em substituição ao álcool, hipoclorito de sódio a $1 \%$, já que este também possui ação desinfetante em pisos e pode ser uma alternativa pelo seu baixo custo e fácil acesso em casos onde o álcool estiver escasso. A solução é encontrada na diluição correta, porém é possível diluir água sanitária em água na proporção de $25 \mathrm{ml}$ para $975 \mathrm{ml}$ ou 2 1/2 colheres de sopa em 1 litro. A fechadura e as chaves devem ser desinfetadas também e com o auxílio do papel toalha, 
friccionar as maçanetas. Deste passo em diante, a porta pode ser fechada.

Imediatamente, o profissional deve se encaminhar para realizar banho de aspersão completo. Deve-se atentar para a higienização dos cabelos e cavidade oral. Por ser transmitido por gotículas e aerossóis, existe a possibilidade de serem retidas pelos fios da face, como cabelo e sobrancelhas. Também, considerando a presença do vírus SARS COV2 na orofaringe ${ }^{15}$, a higienização oral reduz a probabilidade de contaminação.

Não foi encontrado nenhum estudo sobre a eficácia da higienização nasal na redução da contaminação de doenças respiratórias. Por tanto, nenhuma medida específica foi adicionada neste protocolo. Entretanto, esta higienização pode ser adicionada nesta etapa, caso haja comprovação científica de seu benefício.

Para que todas as etapas sejam cumpridas na ordem e com as devidas recomendações, foi desenvolvido um checklist com 19 passos (anexo) para cumprimento deste protocolo que pode ser impresso e afixado na entrada da moradia como um roteiro ao profissional.

\section{Limitações do Estudo}

Como limitação, este estudo encontrou barreiras quanto a sua testagem. Inicialmente, foi considerado que seriam realizados testes laboratoriais por Swab após a aplicação das etapas para confirmar a efetividade do protocolo proposto. Entretanto, como os recursos estão escassos, sendo priorizados para o atendimento aos pacientes suspeitos de COVID-19, e dado emergência pandêmica em se ter um protocolo que padronize os cuidados do profissional ao chegar a casa, foi considerado que a fundamentação teórica já seria o suficiente para a publicação deste estudo.

\section{Contribuições para a Prática}

Este protocolo contribui para a segurança do profissional e de seus familiares, diante da pandemia do novo coronavírus. Como enfrentamento à pandemia e as doenças epidêmicas, a padronização do protocolo de higienização permite a redução da propagação do vírus, seu controle e a proteção dos profissionais de saúde expostos nos hospitais e clínicas, reduzindo assim, os afastamentos da atividade laboral.

\section{CONCLUSÃO}

Uma padronização como este protocolo é importante para a segurança coletiva em meio a uma pandemia. Segui-lo reduz as chances de subjetivismo neste processo e, por estar fundamentado em pesquisas científicas, o protocolo permite maior segurança para os profissionais de saúde em ambiente domiciliar na prevenção contra a COVID-19.

Como as etapas e suas recomendações são verdadeiramente simples de serem seguidas, assim como seus insumos são de fácil aquisição, este protocolo se mostrou útil, não só a ser realizado pelos profissionais de saúde, como também aos profissionais expostos a COVID-19 em outros ambientes e até a população em geral.

Recomenda-se que este protocolo seja testado e utilizado como base para se adequar às diversas realidades na atual situação, mesmo que haja a inclusão de novas etapas, se necessário. Novos estudos para a validação deste protocolo já estão em execução.

Contribuições dos Autores: Vitor Gomes de Matos Gomes: a) concepção e/ou desenho do estudo; b) coleta, análise e interpretação dos dados; c) redação e/ou revisão crítica do manuscrito; d) aprovação da versão final a ser publicada. Pâmela Costa Pinto dos Santos: c) redação e/ou revisão crítica do manuscrito.

\section{REFERÊNCIAS}

1. World Health Organization. Coronavirus disease 2019 (COVID19)- :Situation report -51. 2020 [ cited 2020 apr 18] . Avaliable from : https://www.who. int/docs/default-source/coronaviruse/situation-reports/20200311-sitrep-51-covid-19.pdf

2. Rutala WA, Weber DJ. Focus on Surface Disinfection When Fighting COVID-19. 2020 [cited 202018 april] Available from https://www.infectioncontroltoday.com/covid-19/focus-surface-disinfection-when-fighting-covid-19
3. Medeiros ABA, Enders BC, Lira ALBC. Teoria Ambientalista de Florence Nightingale: Uma Análise Crítica. Esc. Anna Nery [Internet]. 2015 set [citado em 18 de abril de 2020]; 19( 3 ): 518-524. Disponível em: http://www.scielo.br/scielo.php?script=sci_ arttextEpid=S1414=81452015000300518-Elngen. https://doi.org/10.5935/1414-8145.20150069

4. World Health Organization. Modes of transmission of virus causing COVID-19: implications for IPC precaution recommendations. 2020 [cited 202018 april] Available from https://www.who. 
int/publications-detail/modes-of-transmission-of-virus-causing-covid-19-implications-for-ipc-precaution-recommendations

5. Recomendações da Associação de Medicina Intensiva Brasileira para a abordagem do COVID-19 em medicina intensiva. [citado em 17 de abril de 2020] Disponivel em: https://www.amib.org.br/fileadmin/user_upload/amib/2020/abril/04/Recomendacoes_AMIB04042020_10h19.pdf

6. Ministério do Trabalho e Emprego (BR). Portaria no 485, de 11 de novembro de 2005. Aprova a norma regulamentadora $\mathrm{n}$ ㅇ 32 (Segurança e saúde no trabalho em estabelecimentos de saúde) [Internet]. Diário Oficial da República Federativa do Brasil. 2005 Nov [citado em 18 de abril de 2020]. Disponivel em: http://www.mte.gov.br/legislacao/ normas_regulamentadoras/nr_32.pdf

7. Ministério da Saúde(BR). NOTA INFORMATIVA № 3/2020Secretaria de Atenção Primária à Saúde Departamento de Saúde da Familia Coordenação-Geral de Garantia dos Atributos da Atenção Primária ; 2020. [citado em 17 de abrial de 2020]. Disponivel em: https://www.saude.gov.br/images/ pdf/2020/April/04/1586014047102-Nota-Informativa.pdf

8. São Paulo. Secretaria da Saúde.Manual técnico: procedimento e legislação para risco biológico - Biossegurança na saúde nas Unidades Básicas de Saúde/ Secretaria da Saúde, Coordenação da Atenção Básica.2. ed. São Paulo: SMS; 2014. [citado em 17 de abril de 2020] Disponivel em: https:// www.prefeitura.sp.gov.br/cidade/secretarias/ upload/saude/arquivos/legislacao/Biosseguranca230915.pdf

9. Agência Nacional de Vigilância Sanitária (ANVISA). Nota Técnica GVIMS/GGTES/ANVISA № 04/2020 - Orientações para serviços de saúde: medidas de prevenção e controle que devem ser adotadas durante a assistência aos casos suspeitos ou confirmados de infecção pelo novo coronavírus (Sars-cov-2). 2020[citado em 18 de abril de 2020]. Disponivel em: http://portal.anvisa.gov.br/documents/33852/271858/Nota+T\%C3\%A9cnica+n+04-2020+GVIMSGGTES-ANVISA/ab598660-3de-

\section{4-4f14-8e6f-b934lc196b28}

10. Ministério da Saúde (BR). Protocolo de Tratamento do Novo Coronavírus (2019-nCoV). [publicação online], 2020 [citado em 18 de abril de 2020]. Disponivel em: https://portalarquivos2. saude.gov.br/images/pdf/2020/fevereiro/05/ Protocolode-manejo-clinico-para-o-novo-coronavirus-2019-ncov.pdf

11. Graziano UM, Graziano KU, Pinto FMG, Bruna COM, Souza RQ, Lascala CA. Eficacia de la desinfección con alcohol al 70\%(p/v) de superficies contaminadas sin limpieza previa. Rev. Latino-Am. Enfermagem [Internet], 2013 Apr [cited 2020 Apr 18] ; 21( 2 ): 618-623. Available from: http://www.scielo.br/scielo.php?script=sci_arttextEpid=S0104-11692013000200618\&lng=en

12. Silva JFT. Avaliação da remoção de microorganismos termotolerantes utilizando radiação solar. Trabalho de Conclusão de Curso (Bacharelado em Engenharia Civil). Delmiro Gouveia/AL: Universidade Federal de Alagoas, 2017. [citado em 17 de abril de 2020] Disponivel em: http://www.repositorio.ufal.br/bitstream/riu$\mathrm{fal} / 3687 / 1 /$ Avalia\%C3\%A7\%C3\%A3○\%20da\%20 remo\%C3\%A7\%C3\%A30\%20de\%20microorganismos\%20termotolerantes\%20utilizando\%20 radia\%C3\%A7\%C3\%A3०\%20solar.pdf

13. Perussi JR. Inativação fotodinâmica de microrganismos. Química Nova [revista em internet],2007 [ citado em 18 de abril de 2020]; 30 (4): 988-994.Disponivel em: http://www. scielo.br/scielo.php?script=sci_arttextEpi$d=S 0100-40422007000400039$

14. 42. Lytle CD, Sagripanti JL. Predicted inactivation of viruses of relevance to biodefense by solar radiation. J Virol. 2005 Nov;79(22):1424452. http://dx.doi.org/10.1128/JVI.79.22.1424414252.2005 pmid: 16254359

15. Wang, W., Xu, Y., Gao, R., et al. Detection of SARS-CoV-2 in different types of clinical specimens. JAMA. Publicado online em 11 de março de 2020. doi: 10.1001 / jama.2020.3786. Disponivel em: https://jamanetwork.com/journals/jama/ article-abstract/2762997 


\section{CHECK LIST - PROTOCOLO COVID-19 PARA HIGIENIZAÇÃO DE PROFISSIONAL DE SAÚDE NO AMBIENTE DOMICILIAR}

Desenvolvido por: Vitor Gomes de Matos Gomes e Pâmela Costa Pinto dos Santos

\begin{tabular}{|c|c|c|}
\hline AÇÃO & MATERIAIS UTILIZADOS & JUSTIFICATIVA \\
\hline
\end{tabular}

Ambiente Hospitalar - ao sair do plantão (após protocolo institucional de desparamentação)

\begin{tabular}{|c|c|c|}
\hline Retirar fômites e roupa hospitalar & & \\
\hline $\begin{array}{l}\text { Guardar roupas hospitalares do } \\
\text { avesso e dentro de uma sacola plás- } \\
\text { tica/porta jaleco } \\
\text { OU } \\
\text { Descartar roupa hospitalar em local } \\
\text { indicado pela instituição }\end{array}$ & $\begin{array}{l}\text { Saco plástico } \\
\text { OU } \\
\text { Porta jaleco lavável }\end{array}$ & $\begin{array}{l}\text { Evita o transporte de patógenos } \\
\text { para ambientes públicos através de } \\
\text { roupas e objetos contaminados }\end{array}$ \\
\hline $\begin{array}{l}\text { Realizar higiene básica das áreas } \\
\text { descobertas pela roupa hospitalar } \\
\text { OU } \\
\text { Tomar banho na instituição }\end{array}$ & $\begin{array}{l}\text { Água } \\
\text { Sabão neutro } \\
\text { Toalha }\end{array}$ & $\begin{array}{l}\text { Reduz parte da carga patogênica do } \\
\text { corpo do profissional }\end{array}$ \\
\hline Vestir roupas limpas & Roupas de uso diário/comum & $\begin{array}{l}\text { Impede a recontaminação do profis- } \\
\text { sional pelas roupas usadas }\end{array}$ \\
\hline $\begin{array}{l}\text { Utilizar máscaras descartáveis ou de } \\
\text { pano reutilizáveis }\end{array}$ & $\begin{array}{l}\text { Máscara descartável } \\
\text { OU } \\
\text { Máscara de pano reutilizável }\end{array}$ & Reduz a transmissão de gotículas \\
\hline
\end{tabular}

Ambiente domiciliar (a serem realizados no perimetro de segurança)

\begin{tabular}{|c|c|c|}
\hline $\begin{array}{l}\text { Comunicar aos moradores da resi- } \\
\text { dência que está chegando, } 10 \text { minu- } \\
\text { tos antes sua chegada à residência } \\
\text { (Se profissional morar sozinho, pular } \\
\text { este passo) }\end{array}$ & $\begin{array}{c}\text { Aparelho de comunicação (celular) } \\
\text { Participante (Morador) }\end{array}$ & $\begin{array}{l}\text { Permite que os moradores esvaziem } \\
\text { sala, corredores e banheiro e que } \\
\text { contenham animais e crianças }\end{array}$ \\
\hline $\begin{array}{l}\text { Solicitar o posicionamento de ven- } \\
\text { tilador ligado em direção à porta, } \\
\text { aproximadamente } 2 \text { metros de dis- } \\
\text { tância, com o fluxo de ar contra o } \\
\text { rosto do profissional* }\end{array}$ & $\begin{array}{c}\text { Ventilador elétrico } \\
\text { Participante (Morador) }\end{array}$ & $\begin{array}{l}\text { O fluxo de ar impele gotículas emi- } \\
\text { tidas pelo profissional para o am-- } \\
\text { biente externo durante as etapas de } \\
\text { higienização }\end{array}$ \\
\hline $\begin{array}{l}\text { Abrir completamente a porta, man- } \\
\text { tendo a chave pendurada na fecha- } \\
\text { dura }\end{array}$ & - & $\begin{array}{l}\text { Permite troca de ar entre os ambien- } \\
\text { tes e a formação de fluxo de ar do } \\
\text { ambiente interno para externo }\end{array}$ \\
\hline $\begin{array}{l}\text { Remover, higienizar e armazenar } \\
\text { sapatos em ambiente externo }\end{array}$ & $\begin{array}{l}\text { Álcool 70\% (todos os modelos) } \\
\text { OU } \\
\text { Hipoclorito } 1 \% \text { (sapatos emborracha- } \\
\text { dos) }\end{array}$ & $\begin{array}{l}\text { Reduz a transmissão de sujidades e } \\
\text { patógenos para o ambiente domés- } \\
\text { tico }\end{array}$ \\
\hline
\end{tabular}




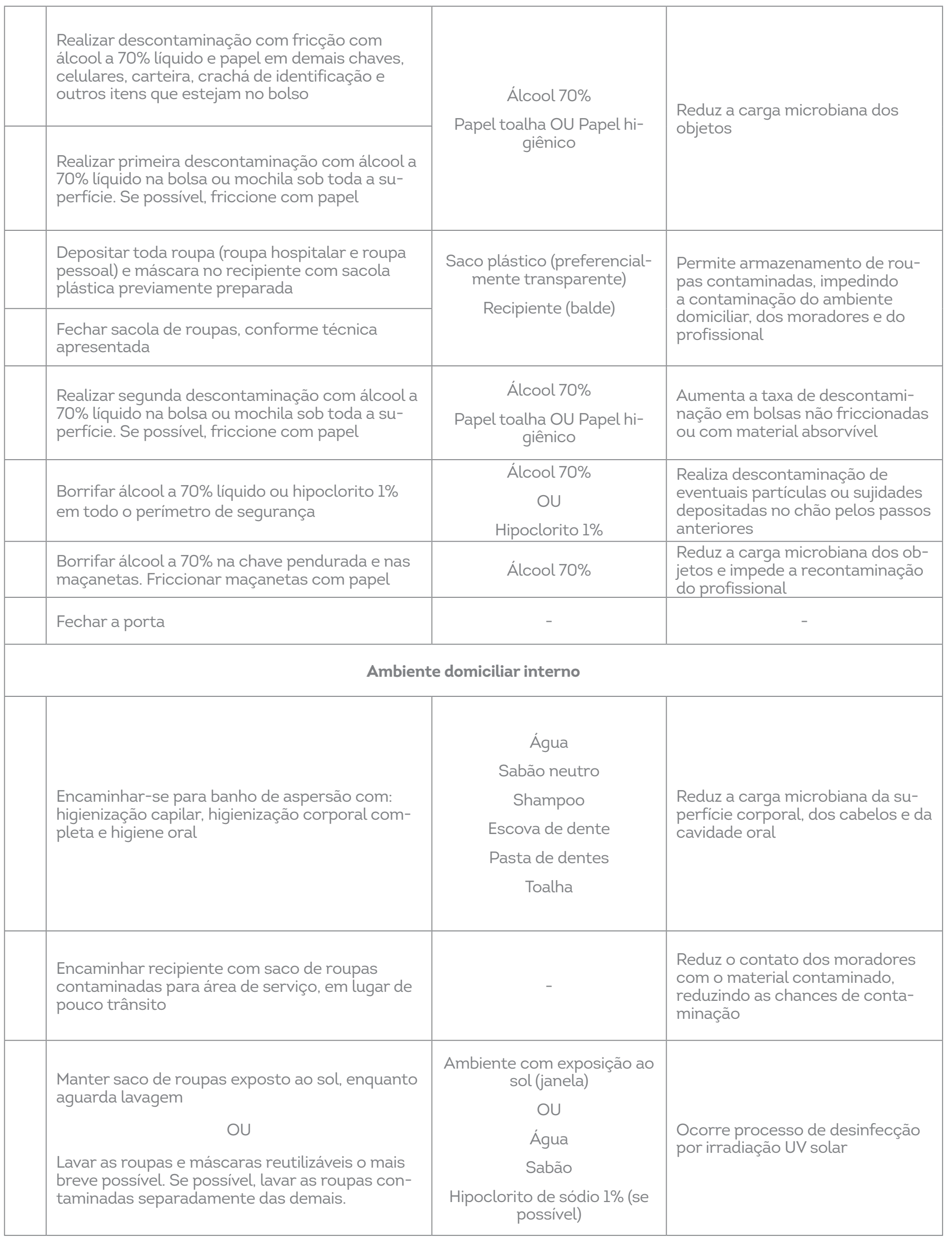

